\title{
CARTOFILIAS URBANAS
}

\author{
Urban Cartophilies
}

Cartofilias Urbanas

Ronaldo DE Moraes BRILHANTe

\begin{abstract}
Resumo: Um modo de ensinar-aprender que não pertence a especialistas, mas a sujeitos interessados em compartilhar-aprimorar os seus saberes sobre as coisas. Esse é um dos propósitos humanos que define a pedagogia freireana e que encaminha o esboço aqui proposto de uma prática de conhecimentos referenciada nas relações afetivas entre os indivíduos e seus ambientes de experiências, de histórias e memórias. Freire nos invoca ao desconforto ocasionado pelo afastamento entre-disciplinas-diversas e nos sugere não uma nova disciplina, mas sim uma determinada "indisciplina”, já que, também, ao senso comum é permitida a palavra num necessário embate entre-idéias. As linhas de pensamento enquanto instrumentais analíticos remetem a separações nas formas de saber; entretanto, enquanto elementos de um campo, ou jogo complexo de complementaridades, podem ser apreendidas como dimensões interdependentes capazes de resguardar um suposto entendimento amplo sobre o mundo em que vivemos. Por isso podemos corresponder a prática freireana a uma pedagogia de encontros, que realiza, simultaneamente, prática de ensino e reelaboração de saberes já feitos. Uma dimensão de saber paralela, independente, porém nutrida das dimensões especializadas. Palavras-chave: Planejamento urbano - aspecto social; Percepção geográfica; Patrimônio cultural - Proteção - Estudo e ensino.
\end{abstract}

Resumen: Una forma de enseñar y aprender que no pertenece a los expertos, pero las personas interesadas a compartir, mejorar sus conocimientos acerca de las cosas. Este es uno de los propósitos humanos que definen la pedagogía de Freire y hacia adelante aqui lo esbozo de un conocimiento práctico que se hace referencia en las relaciones afectivas entre los individuos y sus entornos de experiencias, historias y recuerdos. Freire invoca el malestar causado por la separación entre disciplinas diversas y no hacen alusión a una nueva disciplina, sino una cierta "falta de disciplina", como también se le permite decir un choque entre las ideas es necesario el sentido común. Las líneas de pensamiento como instrumentos de análisis se refieren a las separaciones en las formas de conocimiento; sin embargo, como parte de un campo, o juego complejo de complementariedades que pueden ser percibidos como dimensiones interdependientes capaces de proteger a un presunto amplia comprensión del mundo en que vivimos. Así podemos hacer coincidir la práctica freireana a una pedagogía reuniones, que realiza tanto la práctica docente y reelaboración de conocimientos ya realizados. Una dimensión de saber paralela, Independiente, pero nutrida de las dimensiones especializadas. Palabras-clave: Aspecto de planificación social urbana; Percepción geográfica; Patrimonio cultural-protección-estudio y enseñanza.

Abstract: One way of teaching-learning that does not belong to experts, but interested individuals to share, enhance their knowledge,
improve on things. This is one of the human purposes that defines Freire's pedagogy and forwards here proposed outline of a
practical knowledge referenced in the emotional relationships between individuals and their experiences environments, stories
and memories. Freire invokes the discomfort caused by the clearance between disciplines, diverse and does not hint at a new
discipline, but a certain "lack of discipline", as also the common sense is allowed to say a necessary clash between ideas. The
lines of thought as instrumental analytical separations refer to the ways of knowing, but as part of a field, or complex set of
complementarities, can be seized as interdependent dimensions capable of protecting a supposed broad understanding of the real
data. So we can match the practice freireana a pedagogy of meetings, which performs at the same time practice of teaching and
reworking of knowledge already made. One dimension of knowing parallel, independent, but nourished the size specialist. What
we mean as a re-education of passions, woven-the relationship between wealth: the experiences, stories and memories in what is
perceived in environments experienced. Keywords: Urban planning - social aspects; Geographical perception; Cultural heritage - protection - study and teaching.

\section{Introdução}

Esta pesquisa se origina da necessidade de reflexão acerca de um modo de ensino específico baseado no pensamento de Paulo Freire, que apresenta como mote principal os elos afetivos estabelecidos entre os educandos e os ambientes onde se realizam suas experiências. O que se propõe é uma derivação da metodologia educativa freireana, com o objetivo de municiar procedimentos de ensino voltados às questões ambientais de modo geral. De acordo com esta prática ao educador cabe propiciar elos entre as experiências individuais e as coletivas dos educandos em contextos diversos, com o objetivo de estimular a uma reflexão ampla, no sentido de estabelecer ligações entre relações locais e globais. Caso isso seja devidamente feito, desfigura-se, por consequência, aquilo que na educação tradicional podemos considerar como sendo algo a ser relativizado: discute-se uma razão na qual o aprendizado 
se dá abstratamente, por intermédio de uma relação de transmissões de conteúdos, segundo a qual, como bem disse Freire em sua "Pedagogia do Oprimido", recipientes cheios são responsáveis pelo preenchimento de recipientes vazios. $\mathrm{O}$ educador deve, antes, respeitar-propiciar o transbordamento de percepções, valores, histórias e memórias, permitindo-lhes espaço na difícil tarefa de produção de conhecimentos.

O primeiro momento do método freireano refere-se ao levantamento do universo daquela realidade onde a prática educativa será desenvolvida. Desse exercício procura-se extrair elementos vinculados às relações do grupo com o qual se iniciará o processo educativo. As questões que se apresentam como significativas são reconhecidas como sendo as “temáticas geradoras”. É a partir delas que educandos e educadores desencadeiam a prática pedagógica.

O levantamento freireano se ressalta por seu caráter dialético, não destaca dados isolados, mas sim elementos em relação, que têm como termo articulador a experiência humana. Uma forma de trabalho, uma ação, um contato entre sujeitos, um lugar, podem ser sempre reconhecidos, mediados, pelos ambientes que os comportam. De maneira geral, os ambientes humanos podem ser considerados como as textualidades de suas experiências. Os ambientes humanos são compostos, fundamentalmente, por um conjunto de infinitas relações, que lhes dão forma, conteúdo e sentido.

Neste texto exploraremos o quanto a abordagem fenomenológica pode ser utilizada de maneira complementar a prática educativa aqui investigada, tanto no sentido de aprimorar elementos do ponto de vista analítico, quanto instrumentais ao exercício didático; de modo particular a perspectiva da experiência de Yi-Fu Tuan tem nos permitido importantes desdobramentos. A abordagem de Tuan especifica melhor o mundo histórico-cultural-psicológico apreendido pelo educando, ao relacionar aquilo que é percebido com as especificidades reconhecidas nos espaços e nos lugares. Sua aproximação à psicologia da aprendizagem cobre uma lacuna importante para a prática que pretendemos.

A perspectiva da experiência de Tuan nos permite não só recursos para que possamos reconhecer elementos de forma mais apurada, mas também nos propicia outros diversos temas para a produção de laços de diálogos no decorrer da prática docente. A preocupação com a reconstituição das histórias dos educandos em relação aos seus meios, os valores que afloram atitudes nos proporcionam temas adicionais e variados para o aprendizado. Freire faz da pedagogia um espaço para trocas afetivas, mas não se preocupa em aprofundar o papel dos laços afetivos no processo de aprendizado. Por outro lado, Tuan $(1980 ; 1983)$ procura sistematizar esses elos, pois sabe o quanto eles são importantes para a formulação de processos de ensino.
Em 'Topofilia' (1980), assim como em 'Espaço e Lugar' (1982). Tuan atribuía grande importância à questão do aprendizado, à aquisição de experiência com a idade. Se consultarmos mais trabalhos do autor, veremos que essa preocupação está relacionada com a psicologia da aprendizagem de Piaget. Esta corrente da psicologia é explicitamente citada em 'Humanistc Geography' (1976), quando o autor enuncia que a geografia humanista está preocupada com a conscientização humana e com o aprendizado. (...) A ênfase do autor é para a aprendizagem como modo de estruturar o mundo (Holzer, 1992, p. 9).

Os conceitos de espaço e lugar favorecem uma melhor abordagem daquilo que é percebido com efetivo valor pelo educando; os seus lugares de predileção têm um grande potencial de carregar o que é significativo para as histórias e memórias das pessoas. Freire dizia que o "homem aprende em comunhão mediatizado pelo mundo" (Freire, 2005a, p.78), o problema consiste no reconhecimento da generalidade que a conceituação de mundo pode receber. Os problemas percebidos no mundo não são os mesmos, não têm a mesma intensidade e significação, nem mesmo para indivíduos com características muito próximas. Tuan, por outro lado, nos convida a observar de modo específico essas diferenças, a partir das características de gênero e idade que passaram a ser norteadoras para a formulação dos trabalhos de campo que se seguiram em nossa pesquisa. A seguir apresentamos os procedimentos iniciais desse estudo, com a sistemática das entrevistas visando a leitura do universo ambiental de indivíduos em faixas etárias diversas, além de alguns recortes das entrevistas para uma melhor compreensão da proposta.

\section{Método}

O estudo de campo foi iniciado em duas instituições que prestam trabalhos complementares ao ensino fundamental, em localidades no Estado do Rio de Janeiro. A pedido de seus diretores, aqui não serão divulgados os nomes desses estabelecimentos de ensino, bem como os nomes dos entrevistados. Ambas as instituições desenvolvem trabalhos com crianças em grupos etários próximos, de 8 a 11 anos e de 7 a 13 anos, respectivamente. Foram entrevistadas vinte e cinco crianças na primeira localidade (9 meninos e 16 meninas) e vinte e nove na segunda localidade (14 meninos e 15 meninas). Aqui apresentamos uma primeira sistematização dos resultados de nosso levantamento do universo ambiental das crianças, bem como uma primeira leitura sob a luz da perspectiva experiencial de Yi-fu Tuan.

Como foi inicialmente estabelecido, as entrevistas com os responsáveis pelas crianças ocorrerem conforme elas falavam de modo espontâneo das experiências de seus pais ou avós. Não foi preciso entrevistar tanto adultos quanto crianças, dado que, a partir dos contatos com eles, 
nos preocupamos em aprofundar algumas temáticas que servissem de exemplo ao estudo. Ficou estabelecido que todos os temas advindos dos relatos seriam representativos para o levantamento. Procuramos abordar igual número de homens e mulheres.

Como estabelecido anteriormente, as questões relativas as experiências com os ambientes seriam apresentadas segundo formulações que, em primeiro lugar, teriam que ser genéricas e, em segundo, teriam que corresponder à assimilação tanto de crianças quanto de adultos. Os questionamentos para as crianças foram compostos de uma pergunta e uma atividade apresentados em folhas no formado A4: 1 . O que considera importante para o lugar onde mora e por quê? (Que se não fosse compreendida de pronto, desdobrava-se para outro questionamento apresentado verbalmente) o que gosta no lugar onde mora? Onde mais gosta de ir, de ficar com seus pais ou amigos? 2. Faça um mapa mostrando o caminho que faz de casa até a escola e também até os lugares que mais gosta de ir.

Antes de abordarmos os conteúdos das entrevistas, é interessante nos atermos sobre os procedimentos específicos a partir dos quais definimos os primeiros exercícios práticos, o que denominamos de entrevistas lúdicas. De acordo com o procedimento freireano a prática de campo se divide em diversos momentos. Num primeiro, é feito o levantamento dos temas que desencadearão o processo de aprendizagem; num segundo os grupos são reunidos para discutir sobre o como experienciam aqueles temas em seus cotidianos.

O método consiste no aprofundamento de questões comuns. Os educandos são levados a compreender de forma mais apurada o modo como aqueles temas se realizam, a partir do momento em que miram (veem em distanciamento, relembrando a acepção freireana) o como os fenômenos descritos ocorrem na vida do outro, bem como na de cada um. Para essa observação Freire utilizava fotografias, filmes, gravações, desenhos, que remetiam àquelas realidades vivenciadas. A esse momento de visualização, análise e discussão conjunta se denominava "círculos de cultura". Nas relações que pudemos estabelecer com as crianças e com os adultos desenvolvemos a primeira etapa de levantamento e avançamos um pouco no segundo, momento em que sugerimos algumas interlocuções.

A gravação das entrevistas em vídeo e em fita cassete, além de nos ter permitido o registro de uma boa documentação, nos fez perceber uma ludicidade a que não estávamos nos atentando desde os primeiros momentos de ida a campo. Com as crianças, os questionamentos iniciais eram feitos da seguinte forma: $1^{\circ}$ passo - expressões a partir de desenhos (mapa dos lugares que achava mais importantes / que gostava); $2^{\circ}$ passo - relatos escritos (escrever os por quês da consideração por aqueles lugares); $3^{\circ}$ passo - relatos gravados em $\mathrm{k} 7$ (resposta verbalizada dos mesmo questionamento do $2^{\circ}$ passo).

\section{Análise das entrevistas}

Foi interessante perceber algumas crianças, como K (9 anos), por exemplo, que fez um desenho bastante rico em elementos, enquanto que no seu relato escrito não julgou nada que tinha desenhado como sendo importante; mas depois, quando foi perguntado com o gravador, se sentiu a vontade para falar um pouco mais:

$\mathrm{R}$ - isso aqui é o que? / K - igreja / R - você vai nessa igreja? / K - não / R - você a acha bonita? / K - aham / $\mathrm{R}$ - e isso aqui o que é? / $\mathrm{K}$ - prefeitura / $\mathrm{R}$ - e nesse mapa que você fez, qual o lugar que mais gosta, que te chama a atenção? / K - a escola / R - e por que? / K - porque a gente aprende mais... com educação / $\mathrm{R}$ - você conhece o Centro Histórico / K -conheço / R - o que você acha de lá? / K - bonito / R - o que mais você gosta lá? / $\mathrm{K}$ - a Capelinha...

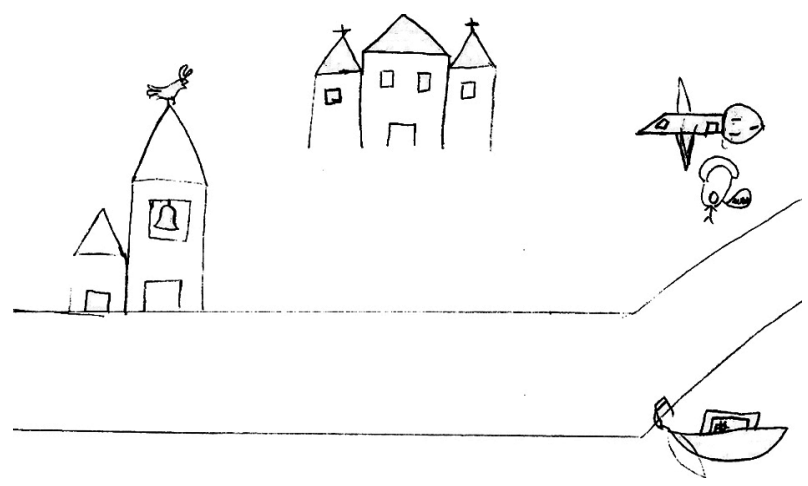

Noutro momento, quando reproduzimos as gravações de suas entrevistas, mesmo alguns mais tímidos se interessaram em falar mais sobre aquilo que haviam expressado em seus mapas. Acrescentavam outros elementos por conta própria ou em decorrência das perguntas que fizemos. Como não havia o propósito de analisar comparativamente os relatos, não tínhamos de nos preocupar com a rigidez de questionamentos muito uniformes. Então, dependendo daquilo que falavam, começamos a encaminhar perguntas mais personalizadas.

Essa dinâmica com o gravador no primeiro trabalho de campo permitiu boas leituras e aferições das possibilidades desse recurso; contudo, foi com o uso da filmadora, já no segundo momento de campo, que pudemos observar um bom salto qualitativo quanto ao procedimento: os temas foram depurados de forma mais aprofundada na medida em que, gradualmente, iam sendo experimentados recursos de mídias diversas.

No segundo campo, fizemos diversos exercícios com o uso do vídeo e gravador k7, em conjugação. Neste momento sugeríamos para que falassem um pouco mais sobre seus desenhos, sobre aqueles lugares que estavam destacando, mas, de maneira diversa pedíamos para que uns entrevistassem os outros. Esse movimento foi 
determinante para que o trabalho confluísse com aquilo que é fundamental na prática freireana: quando o educando começa a se sentir o sujeito da investigação, e para isso a curiosidade inerente à criança ajuda, de objetos passam a sujeitos da ação. Então tanto com o gravador, e principalmente com vídeo, ocorreu o aprofundamento da análise daqueles lugares. Um feito éramos nós lhes perguntando sobre as suas percepções, atitudes e valores (Tuan, 1980) em relação àqueles lugares; outro eram eles se questionando, suas perguntas entre si foram mais incisivas em relação àquilo que interessava à pesquisa:

K 9 anos $\Rightarrow$ B 10 anos

K - O que você faz na cachoeira? / B - Brinco, né. Tomo banho. Ralo o joelho, machuco a cabeça... Só, pergunta mais... / K - o que é que você faz na quadra? / B - Nada / K - nem jogar bola? / B - Não, não gosto não. Na hora do queimado, ninguém joga bola pra mim e eu também não jogo bola pros outros. / K - você gosta de basquete? / B Huhum / K - faz alguma cesta? / B- Não, sou muito ruim.

Para o aprofundamento da análise da forma como eles experienciam o espaço e que valores agregam a seus lugares de predileção, as entrevistas deles entre si vieram a ser um passo muito construtivo. É interessante notar que a objetividade do entrevistador é, em certo modo, mais apurada do que nós pesquisadores poderíamos exercitar. Esse apuro se dá pelo simples fato de o entrevistador assumir, já no ato da pergunta, fazer parte da vida do entrevistado, inclusive sabendo de seus "podres", que faz questão de revelar.

\section{$\mathrm{L} 10$ anos $\Rightarrow$ M10 anos \\ L - Você desenha na mesa? / M - Desenho / L- o que? / M - Um monte de bobeira / L - fala o que é? / M - Não posso falar não... / L - fala... / M - piru / L - não pode falar isso não... / M - eu sei... / L - o que você desenha mais? / M - A escola, "Rebeldes"... te amo.}

Com isso, também, o número de elementos destacados por cada um cresceu em número e em significação. Quando, junto com grupos em separado, fomos aos lugares destacados nos desenhos, pudemos aprofundar mais algumas questões. Assim, o procedimento associado entre desenho (os mapas mentais), perguntas, entrevistas gravadas com perguntas feitas pelo educador e, em seguida, com perguntas feitas pelos educandos entre si, pode ser definido, até então, como um bom instrumento de leitura de campo a ser praticado com as crianças. E que, por desdobramento, oferece-nos importantes elementos a serem apropriados como recursos didáticos.

É interessante perceber a reação das crianças ao se ouvirem e se verem nos vídeo (o tão importante movimento do mirar-se da perspectiva freireana ${ }^{1}$. Elas se surpreendem com uma enorme intensidade, como se estivessem se redescobrindo: como falam, como cantam, como se movimentam. Elas demonstraram grande interesse em serem entrevistadas, e, principalmente, de se verem e ouvirem depois nas entrevistas. Umas brincavam, outras caçoavam das outras e até brigavam, atitudes que descrevem com fidelidade uma enorme quantidade de valores infantis ainda em formação.

Com as entrevistas filmadas na segunda localidade, pudemos desenvolver outro exercício na primeira localidade. O que começamos a compreender como um "círculo de cultura" derivado da abordagem freireana; feito de maneira ampliada entre pessoas de gêneros, idades e lugares diferentes. A partir dos desenhos que as crianças fizeram convidamos alguns pais, avós e amigos para falarem sobre aqueles lugares destacados. Os relatos dos adultos foram muito importantes para o desdobramento dos temas das crianças.

As entrevistas com os adultos foram feitas em duas etapas, a primeira gravada em $\mathrm{k} 7$ e a segunda em vídeo. Algumas entrevistas filmadas com os adultos da segunda localidade foram apresentadas para as crianças, que passavam a conhecer os lugares destacados pelas crianças da primeira localidade. Após a apresentação dos vídeos pedimos para que as crianças elaborassem perguntas. Esse exercício possuiu dois objetivos:

1) Demonstrar o início de um processo dialógico; para isso sugerimos que as crianças de uma localidade respondessem, via internet, aos questionamentos feitos pelas outras. Logicamente as interlocuções se deram na medida em que tivemos como mediá-las, contudo, como demonstrativo, o exercício foi bem sucedido. As crianças nesta idade já estão participando de laboratórios de informática e os exercícios dialógicos podem se configurar em bons instrumentos para o estudo de conteúdos diversos;

2) Com esse exercício pudemos também perceber o interesse de grande parte das crianças por conhecer lugares e pessoas que nunca tinham visto, mas que, de uma maneira ainda pouco apreensível, lhes atraia a atenção. ${ }^{2}$

\footnotetext{
Movimento o qual Tuan, confluindo com Freire, observa como fundamental para a construção do conhecimento: "A habilidade espacial se transforma em conhecimento espacial quando podem ser intuídos os movimentos e as mudanças de localização. Andar é uma habilidade mas, se eu puder me 'ver' andando e se eu puder conservar esta imagem em minha mente que me permita analisar como me movo e que caminho estou seguindo, então eu também tenho conhecimento" (Tuan, 1983, p. 77) - assim como a formação do conhecimento está relacionada com esse mirar, podemos considerar que, a construção do saber está associada à atitude que possa ser concebida em relação a esse conhecimento.

2 Tuan diz que "o horizonte geográfico de uma criança expande à medida que ela cresce, mas não necessariamente passo a passo em direção à escala maior. Seu interesse e conhecimento se fixam primeiro na pequena comunidade local, depois na cidade, saltando o bairro; e da cidade seu interesse pode pular para a nação e para lugares estrangeiros, saltando a região. Na idade de cinco ou seis anos, a crianças pode demonstrar curiosidade sobre a geografia de lugares remotos. Como pode apreciar locais exóticos se não tem experiência direta?" (Tuan, 1983, p. 35).
} 
Acredito que esse interesse pela novidade possa vir a ser o combustível para o desencadeamento de um processo mais amplo de formação de conhecimento. Os lugares do outro permitem mediar experiências comuns.

Mas, as entrevistas gravadas representam um material também muito importante para o reconhecimento das histórias locais. Em seus relatos os adultos falavam sobre as histórias daqueles lugares destacados pelas crianças. Histórias que, muitas vezes, as crianças não conheciam; esses casos deram bons desdobramentos.

Em relação aos desenhos, é interessante destacar que as crianças se detinham com mais cuidado, com muita dificuldade, na hora de representar ladeiras, morros e escadarias, pois, enquanto desenho, essa representação era comum a qualquer outra, mas enquanto sentimento corporal era diversa. Nesses pequenos eventos elas demonstravam que não estavam simplesmente racionalizando, escrevendo textualmente uma experiência, mas estavam, também, mentalmente a experimentando. Ou seja, não é arriscado supor que, estavam mirando-se imaginariamente subindo e descendo escadarias e ladeiras no momento do desenho.

Um efeito próximo àquele praticado pelo método freireano, quando os educandos observavam-discutiam, em distanciamento, as realidades por eles vividas com o auxílio de imagens. A partir dessa mirada distanciada propiciam-se vínculos entre o que é, e o que pode vir a ser. Freire dizia que o homem é um ser de admiração. É a partir dessa admiração que, dialogando, problematizando o que vemos, somos capazes de constituir renovadas visões de mundo.

A pedagogia deve primar pela captura desses instantes, em que o humano busca superar os limites de seus saberes sempre em construção. Novas visões de mundo podem ser formadas, na medida em que vivifiquemos, a partir do diálogo, tanto as emoções, quanto os resultados obtidos pelas experiências. Yi-fu Tuan se preocupa em falar sobre a natureza de nossa experiência: da potencialidade do homem em experimentar, em constituir conhecimento a partir dessa experimentação. Essa abordagem geral nos permite uma grande expansão daquilo que podemos extrair do campo como significativo para uma perspectiva educativa calcada na vivência sobre os ambientes. Percepções, valores e atitudes conformam um fluxo de interações complexas capazes de revelar os diferenciados modos com os quais os indivíduos apreendem e interagem com seus meios ambientes. As práticas pedagógicas que se pretendem plurais devem levar em conta essas relações.

Foram entrevistados quatorze adultos, cinco homens e seis mulheres na segunda localidade; um homem e duas mulheres na primeira localidade. Os relatos da primeira diferem, em quantidade de elementos e qualidade descritiva, dos da segunda. Consideramos, preliminarmente, que isso se deve ao modo como abordamos distintamente os dois campos. Na segunda localidade, foram tidas conversas em momentos anteriores às entrevistas. Nessas conversas, o propósito do trabalho foi esmiuçado, o que fez com que os entrevistados compreendessem de uma melhor maneira que estavam fazendo parte da produção de um procedimento de ensino. Possibilitou que se envolvessem de uma forma diferenciada com os propósitos da pesquisa.

As conversas que antecederam às entrevistas possibilitaram também o desdobramento das questões iniciais. Com perguntas que procediam àquelas relativas aos laços de permanência (pedimos que falassem sobre e o que consideravam importante para a história daquele lugar; que fizessem um relato da história da vinda de sua família; que falassem sobre as mudanças percebidas nesse tempo em que viviam ali) passamos a investigar mais profundamente sobre os valores específicos que constituíam os laços de afetividade daquelas pessoas com aqueles lugares.

Logicamente, as conversas anteriores poderiam ser prescindíveis caso estivéssemos somente buscando conhecer questões relativas ao tema proposto. Mas não podemos esquecer que, de acordo com o ir a campo freireano, o que se estabelece não são simplesmente contatos, mas sim relações. É nessas conversas que temos oportunidade de clarificar os objetivos do trabalho. Essa forma de proceder da prática freireana, realce aparentemente simples, constitui um passo fundamental para que aos entrevistados seja permitido articular o movimento capaz de vertê-los de coadjuvantes em protagonistas da ação: eles passam a se reconhecer já no escopo dos questionamentos; são convidados a falar para o entrevistador e, sobretudo, para os grupos de crianças que irão ouvir a suas explicações referentes aos lugares que deseja destacar.

Nas entrevistas com os mais velhos pedíamos o cuidado de explicar de forma simples as histórias, como se estivessem dando uma aula às crianças. Como um primeiro exercício de aproximação o resultado foi bastante satisfatório. O envolvimento dos entrevistados foi crescente, como as entrevistas eram feitas em duas etapas, uma primeira gravada nas residências, e outra filmada nos lugares, os adultos foram muito cuidadosos e receptivos em destacar aqueles elementos que consideravam importantes de forma cada vez esclarecedora.

Os entrevistados eram convidados a falar sobre aquilo que consideravam mais importante sob seus pontos de vistas individuais. Nesta pequena amostragem podemos perceber que esses valores, que são patrimônios individuais e coletivos, que são resultantes de experiências feitas com mais ou menos intensidade nos lugares, afloram a partir das histórias de fixação de suas famílias naqueles lugares; das memórias que resguardam lembranças e reminiscências de passados, quase sempre, calorosos; das histórias oficiais que fazem daqueles lugares importantes, marcos para toda uma região; dos lugares onde se 
revelam nuances que concentram poéticas, lembranças, desejos de encontros nem sempre reveláveis; de mudanças que fizeram com que os lugares perdessem muito de sua aura original; de rejeição tão relacionada à recusa das transformações observadas num dado intervalo de tempo; do trabalho que demarca a luta pela sobrevivência dos e nos ambientes.

A perda foi um tema recorrente entre os idosos. Os espaços perdidos são, também, espaços que permitiam o recordar conhecimentos constituídos. A recordação, no entanto, tornada possível pelo exercício de memória se desestabiliza (Bosi, 2004) quando a ela é sobreposto o sentimento da perda da concretude que só é possível, em intensidade, pela re-experimentação do lugar com a ajuda do encontro dos sentidos: a audição, o tato, o olfato, a visão e o paladar. ${ }^{3}$ Quando observamos o modo como os moradores de Paquetá falam sobre mudança, por exemplo, podemos perceber algumas aproximações e diferenciações. Sobre certos aspectos mudança remete a perda. Citamos alguns trechos:

"Você pegava marisco ali com uma facilidade tremenda. Você mergulhando com uma máscara, você ficava a um metro e meio ou dois metros do fundo e pescava siri. Nós fazíamos uns arpões de pedaços de vergalhão, ficávamos passando na beira da calçada... a dois metros você pegava siri no fundo (...) Antigamente você pegava peixes nobres, pescada amarela, por exemplo, com a mão" P (43 anos - localidade 2).

"Naquela época pegávamos cavalo marinho azul, cavalo marinho branco, cavalo marinho laranja. Pegava ouriço do mar, que furava os pés. Você via as arraias. A poluição acabou com isso tudo, não tem mais. Você jogava rede e pegava peixe de várias qualidades. Agora acabou essa variedade de peixe, a poluição acabou com tudo" A (65 anos - localidade 2).

"Gostava (de pescar), era bem melhor do que hoje. É porque não existia poluição. A fartura de peixe era grande, hoje já não existe. Tem peixe que a garotada não conhece. Cação, raia. Raia vinha na beira da praia. Siri muito, o pescado era farto. Hoje em dia acabou tudo. Muita coisa a garotada não conhece. (...) hoje em dia quem vive de pesca morre de fome. (...) ouriço, cavalo marinho, cobrinha do mar. Estrela do mar. Marisco. Essas crianças de quinze anos de idade já não conhece nada, nada, nada. Tinha aqui na beira da praia” C (54 anos - localidade 1).

\footnotetext{
"Quando retornamos à cena de nossa infância, não somente a paisagem mudou mas também a maneira como nós a vemos. Não podemos recapitular completamente o sentimento essencial de um mundo visual do nosso passado sem o auxílio de uma experiência sensorial que não mudou; por exemplo, o forte cheiro da alga marinha apodrecendo" (TUAN:1980, p. 12)
}

"Antigamente, quando eu vim pra cá conhecer eu tinha quinze anos, e saia para dar uma volta e conhecia todo mundo. Todo mundo conhecia todo mundo sabia onde estava todo mundo" E (43 anos - localidade 1).

"Como eu converso com o C, quando viemos para Paquetá, aqui na Praça, tinha muita árvore lá. As árvores caíram e eles não plantaram outras no lugar. Agora devem ter umas três ou quatro e quando caírem aquelas vai ficar só aquele coreto lá” A (65 anos - localidade 1).

"A Praia é uma, que não é mais como era. Eu gosto da antiga, dessa nova eu não gosto, de quando não tinha esse aterro. (...) a gente não precisava nem pegar barco, tinha (peixe) aqui na beira da praia. Agora não temos mais. Acabou tudo, tudo, tudo. A poluição acabou com tudo nosso" M (52 anos - localidade 1).

Com essas citações, podemos perceber que os sentimentos com o lugar se manifestam das mais diversas formas, a intensidade com a qual essa emoção é transmitida vem a ser um primeiro indicativo da amplitude dos elos afetivos. Podem ser descritos pelo "prazer visual efêmero; o deleite sensual de contato físico; o apego por um lugar por ser familiar, porque é o lar e representa o passado, por que evoca orgulho de posse ou de criação; alegria nas coisas devido à saúde e vitalidade animal" (Tuan, 1980, p. 268). Esses prazeres são comuns a homens, mulheres e crianças de lugares distintos. Assim,

"Uma comunidade realmente enraizada pode ter santuários e monumentos, mas é improvável que tenha museus e sociedades para preservar o passado. O esforço para evocar um sentimento pelo lugar e pelo passado frequentemente é deliberado e consciente. Até onde o esforço é consciente, é a mente que trabalha, e a mente - se lhe permitimos exercer seu domínio imperial - anulará o passado, transformando tudo em conhecimento presente”. (Tuan, 1983, p. 219)

\section{Reflexões finais}

Para um bom desenvolvimento da questão poderíamos pedir que os nossos interlocutores explicassem sobre o que aprenderam nesses lugares, que emoções, que saberes, que prazeres nele foram constituídos? Qual o papel político de uma sociedade mais consciente de seus patrimônios (objetos e sentimentos) na preservação desses lugares? Mas o que, em verdade, queremos preservar, serão os lugares ou as experiências adquiridas, os sentimentos aflorados, com eles? Mas, preservados, ou não, os lugares, a pedagogia não poderia se verter num instrumento de revelar-comunicar aquilo que realmente lhes dá substância, contra uma cultura demasiadamente atrelada à imagem? E o que representaria, para a política, para a economia, 
para a sociedade, uma cultura escolar apoiada pela revelação-comunicação das experiências atreladas aos lugares? Que valores humanos poderíamos deduzir desse movimento?

É provável também que esse aprendizado feito no ambiente íntimo, a partir das experiências dos familiares seja mais profundo, assim duradouro, do que aquele praticado nos círculos escolares. Como fazer com que esse ambiente doméstico seja um melhor mediador para o ensino ambiental? Certamente, para isso, a escola deve estar atenta às experiências com as quais os familiares dos alunos podem colaborar para a ilustração de novos aprendizados. Concordando com Tuan, em confluência com Freire: a experiência corporifica a compreensão sobre as coisas.

Não há limites para a construção de novos conhecimentos quando nos dispomos a experienciar os ambientes dialogando com as experiências do outro. Reconhecer que todas essas experiências ambientais são relacionáveis consiste num primeiro passo para a constituição de laços educacionais maiores. Mas, quais são os desafios em comunicar experiências que envolvem sentimentos tão diversos, para indivíduos com expectativas e percepções mais diversos ainda? O foco do discurso na experiência obtida a partir da relação com o ambiente é fator de vantagem para um exercício de trocas mútuas. Entretanto, a dimensão real do desafio que se apresenta só poderá ser mensurada a partir da prática.

Certamente com todo o material que pudemos recolher de nossas entrevistas, sob as luzes de Tuan em conjunto com Freire, teremos elementos para muitos anos de estudos. Por outro lado, se nos dispuséssemos a mergulhar nas questões trazidas por cada desenho, por cada relato e pela conjugação de relações, não teríamos espaço para tecer este quadro geral do método de ensino que pretendemos.

Podemos observar que existe um grande salto de qualidade analítica naqueles casos em que tivemos a oportunidade de fazer entrevistas encadeadas entre crianças - pais - avós, dado que, assim, pode-se verificar o papel do ambiente doméstico na formação de modos de ver o mundo. Quadro que se complementaria se levássemos em conta uma investigação acerca do universo escolar dos menores. Para um procedimento mais apurado seria interessante traçar análises individualizadas por famílias, para depois arranjar os resultados por grupos.

Esse olhar mais cuidadoso sobre as relações familiares, acreditamos, vem a ser fundamental para a construção de procedimentos didáticos voltados à formação de um ambiente de respeito mútuo, distinguindo o que são valores individuais e o que são valores de grupo entre as famílias, nos contextos de suas memórias e histórias. Essa leitura encadeada vem a ser fundamental para a formação de entendimentos pluri-escalares: o saber local distinto do saber global pode ser iniciado a partir da distinção, que de forma lúdica e didática, pode ser estabelecida em sala de aula, onde os alunos devem ser convidados a perceber-apreender diferenças e semelhanças; aproximações, distanciamentos e respeitos.

\section{Referências}

Bachelard, G. (1996). A poética do espaço. São Paulo: Martins Fontes.

Bachelard, G. (1996). A formação do espírito científico. Rio de Janeiro, Contraponto.

Bosi, E. (2004). Memória e Sociedade. Lembranças de Velhos. São Paulo: Companhia das Letras.

Buber, M. (1976). Eu e tu. São Paulo: Cortez e Moraes.

Buber, M. (1983). Do diálogo e do dialógico. São Paulo: Perspectiva.

Freire, P. (2005a). Pedagogia do Oprimido. Rio de Janeiro: Paz e Terra.

Freire, P. (2005b). A Educação na Cidade. São Paulo: Cortez.

Freire, P. (2002). Aprendendo com a própria história. São Paulo: Paz e Terra.

Freire, P. (2000). Pedagogia da Indignação. São Paulo: Editora Unesp.

Freire, P. (1996). Pedagogia da Autonomia. São Paulo: Paz e Terra.

Holzer, W. (1992). A Geografia Humanista - sua trajetória de 1950 a 1990. Dissertação (Mestrado em Geografia). Universidade Federal do Rio de Janeiro / UFRJ-IGEO, Rio de Janeiro, cap. 9.

Linhares, C. \& Trindade, M. N. (2003). Compartilhando o Mundo com Paulo Freire. São Paulo: Cortez: Instituto Paulo Freire.

Tuan, Y. (1982). Espaço e Lugar. São Paulo: Difel.

Tuan, Y. (1980). Topofilia. São Paulo: Difel.

Tuan, Y. (1975). Images and mental maps. Annals of the Association of American Geographers, v. 65, n. 2, p. 205-213.

Ronaldo de Moraes Brilhante - Graduado em Arquitetura e Urbanismo pela Universidade Federal Fluminense, Mestre em Gestão do Espaço Urbano pela Universidade Federal Fluminense; Doutor em Urbanismo pelo Programa de Pós-Graduação em Urbanismo - PROURB/ FAU-UFRJ (2013). Professor Adjunto da Escola de Arquitetura e Urbanismo da Universidade Federal Fluminense. Endereço Institucional: Rua Uruguai, 380 / D / 404. Tijuca, Rio de Janeiro, RJ, CEP: 20510-052. E-mail: rmbrilhante@icloud.com

Recebido em 03.05.16 Primeira Decisão Editorial em 20.06.16 Aceito em 18.09.16 